\title{
Endoscopic treatment of intraluminal ureteral suture with holmium laser
}

\author{
Jorge Panach-Navarrete, María Negueroles-García, José María Martínez-Jabaloyas \\ Department of Urology, University Clinic Hospital of Valencia, Facultat de Medicina i Odontologia, Universitat de València, \\ Valencia, Spain.
}

\begin{abstract}
Summary
Although reconstructive surgery is the most accepted treatment for ureteral injury, there are reports of cases where endourologic treatment led to correct resolution of the problem. We present the case of a female patient aged 72-year-old who was previously underwent sacralcolpopexy because of anterior vaginal compartment prolapse. The patient underwent surgery to remove the mesh, due to the pain she had had since it was placed. A mid-line laparotomy was performed removing completely the mesh. At 48 hours after intervention, the patient started feeling an intense pain in the left renal fossa that was not relieved with anti-inflammatories and morphic drugs. In the diagnostic ureteroscopy, it was found iatrogenic suture of the ureter. Due to the availability of holmium laser, an endoureterotomy was performed in the $12 \mathrm{~h}$ central position on the tip, with laser parameters of $1 \mathrm{~J}-10 \mathrm{~Hz}$. A $6 \mathrm{~F}$ ureteral stent was maintained for one month. During follow-up, the patient remained asymptomatic and without dilation of the left system on imaging tests. Although we accept that open reconstruction is the gold standard treatment for ureteral trauma, we describe holmium laser endoureterotomy as a promising technique to consider in the event of ureteral intraluminal ligation.
\end{abstract}

KEY WORDS: Ureteral trauma; Endourology; Holmium laser.

Submitted 2 February 2021; Accepted 5 February 2021

\section{INTRODUCTION}

Ureteral injury represents only $1-2,5 \%$ of urologic trauma. The main cause of ureteral injury is in $75 \%$ of the cases iatrogenic by urologic, gynaecologic, or colorectal surgery. Ureteral injury diagnosis must be suspected since there are no specific signs to identify it. Patient symptoms will depend on the degree of the wound, location, or the type of damage (perforation, ligation, transection). Computed tomography urography (CTU) and anterograde or retrograde pyelography presents high sensibility for ureteral trauma diagnosis (1).

Although reconstructive surgery is the most accepted treatment for ureteral injury, there are reports of cases where endourologic treatment led to correct resolution of the problem. Various procedures have been described from resolution of urinary leak by means of ureteral stent to ureteral realignment in case of complete transection (1). In this study, we present a case of an iatrogenic ureteral ligation with an intraluminal suture resolved by laser endoureterotomy. Here we describe the key points of the surgery as well as review similar cases reported in literature.

\section{Case report}

We present the case of a female patient aged 72 -year-old who previously underwent sacral-colpopexy because of anterior vaginal compartment prolapse. The patient underwent surgery to remove the mesh, due to the pain she had had since it was placed. A mid-line laparotomy was performed removing completely the mesh.

At 48 hours after intervention, the patient started feeling an intense pain in the left renal fossa that was not relieved with anti-inflammatories and morphic drugs, as well as nausea and vomiting. CT scan showed left uretero-hydronephrosis with complete ureteral dilation from a few centimetres above the bladder. Moreover, it was observed free perirenal fluid. Based on these findings, it was decided emergency surgery performing retrograde pyelography.

During pyelography (Figure 1), it was checked stop in retrograde pass contrast about $4 \mathrm{~cm}$ from the bladder. With the increase of the instillation pressure of contrast in the ureter, a filiform passage of contrast was observed through the stop area. At that time, a ureteroscopy was decided, introducing a $9.5 \mathrm{~F}$ semi-rigid instrument to the problem area (Figure 2). Under direct vision, concentric closure of the ureter lumen could be observed, suspecting iatrogenic suture of the ureter. A guide pass was achieved through the central area of the stenotic area, verifying its correct location with intraoperative fluoroscopy. Due to the availability of holmium laser, an endoureterotomy was performed in the $12 \mathrm{~h}$ central position on the tip, with laser parameters of $1 \mathrm{~J}-10 \mathrm{~Hz}$. Almost instantaneously, the stenotic area was opened, showing the polyglactin suture that entered from the outside of the ureter to the inside and leaving the ureter tract with a good caliber without resistance to the passage of the ureteroscope. In the rest of the ureter no injuries were evidenced.

A $6 \mathrm{~F}$ ureteral stent was maintained for one month. During follow-up, the patient remained asymptomatic and without dilation of the left system on imaging tests.

\section{Discussion}

The use of holmium laser for the endoscopic treatment of intraluminal ureteral sutures has been previously described, with correct resolution in all cases.

The summary of the published literature is summarized in Table 1 (2-5). 


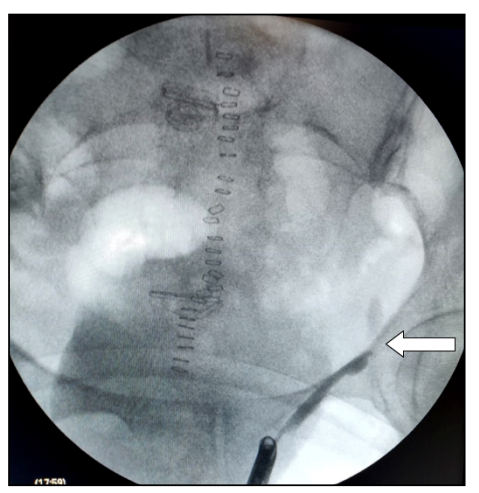

Figure 1.

Retrograde pyelography where a retrograde stop in the contrast passage was found about $4 \mathrm{~cm}$ from the bladder.

By increasing the instillation pressure of contrast in the ureter a filiform passage (white arrow) of contrast was observed through the stop area.

Figure 2.

Image of ureteroscopy.

(A) Guide passage through the stenotic area.

(B) Endoureterotomy with holmium laser in position $12 \mathrm{~h}$ on the guide.

(C) Image of the injured area once the stenosis has been incised.

The white arrow indicates the polyglactin suture, with the gray arrow the area of the ureter wall incised with laser.

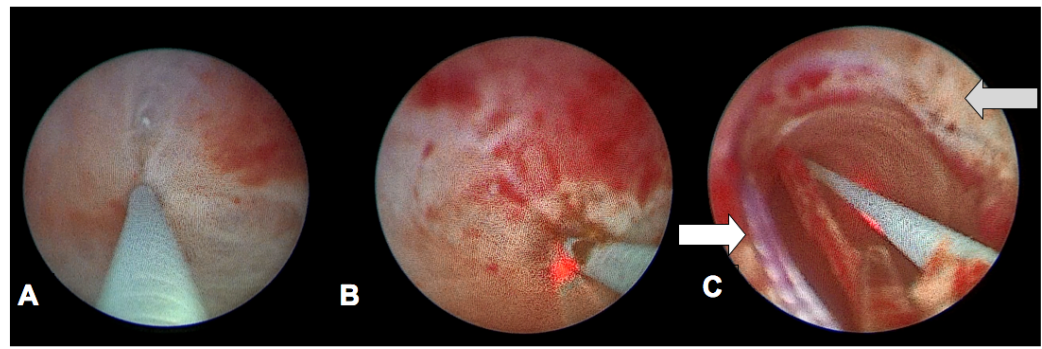

Table 1.

Endoscopic treatment of intraluminal sutures, summary of published cases.

\begin{tabular}{|l|c|c|c|c|c|}
\hline Author & $\begin{array}{c}\text { Number } \\
\text { of cases }\end{array}$ & $\begin{array}{c}\text { Balloon } \\
\text { dilatation catheter }\end{array}$ & $\begin{array}{c}\text { Weeks } \\
\text { of stent }\end{array}$ & Success & $\begin{array}{c}\text { Postoperative } \\
\text { complication }\end{array}$ \\
\hline Hao, Z. (2) & 12 & Yes & 12 weeks & $100 \%$ & No \\
\hline Baǵley, D.H. (3) & 1 & No & 6 weeks & $100 \%$ & No \\
\hline Lawrentschuk (4) & 1 & No & 2 weeks & $100 \%$ & No \\
\hline Klett, D.E. (5) & 1 & No & 8 weeks & $100 \%$ & No \\
\hline
\end{tabular}

As can be seen in the review, endoscopic ureterotomy is a successful surgery which can prevent the patient from a more aggressive surgery.

As shown in Table 1, the use of the balloon dilatation catheter or the weeks of permanence of the stent are not clearly defined. In our experience, the clinical course of the patient was optimal without the use of a balloon and with maintenance of the stent for 4 weeks. From our point of view, it is a simple endourological procedure if you are used to ureteroscopy.

The main limiting factor could be the availability of laser in case of emergency surgery, so the possibility of its use must be foreseen. Although we accept that open reconstruction is the gold standard treatment for ureteral trauma, we describe a promising technique to consider in the context of ureteral intraluminal ligation.

\section{REFERENCES}

1. Bryk DJ, Zhao LC. Guideline of guidelines: a review of urological trauma guidelines. BJU Int. 2016; 117:226-34

2. Hao Z, Zhang L, Zhou J, et al. Minimally Invasive Management of Iatrogenic Ureteral Injuries with Ureteroscope Facilitated by Holmium YttriumAluminum-Garnet Laser. Int Sch Res Notices. 2014; 2014:307963.

3. Bagley DH, Schultz E, Conlin MJ. Laser division of intraluminal sutures. J Endourol. 1998; 12:355-7.

4. Lawrentschuk N, Rogerson J, Bolton DM. Use of holmium laser for removal of an intraluminal ureteric suture. Int J Urol. 2004; 11:916-8.

5. Klett DE, Mazzone A, Summers SJ. Endoscopic Management of Iatrogenic Ureteral Injury: A Case Report and Review of the Literature. J Endourol Case Reports. 2019; 142-144.

\section{Correspondence}

Jorge Panach-Navarrete, MD (Corresponding Author)

jorge.panach@uv.es

María Negueroles-García, MD

maria.negueroles@gmail.com

José María Martínez-Jabaloyas, MD, PhD

marjabaloyas@gmail.com

Department of Urology, University Clinic Hospital of Valencia,

Facultat de Medicina i Odontologia, Universitat de València, Valencia, Spain

Av Blasco Ibáñez, 17, CP 46010 Valencia, Spain 